issue and again in 1938 before the present edition was published. This edition contains about 20 more pages and two more illustrations than the first. The author adopts the scientific method of emphasizing the pathological changes and physio-pathology of the disease in endeavouring to deduce the symptoms from the lesions. He also contributes an admirable chapter on the importance of perimetry and has introduced such "new names as retinosis, choroidosis and perivascular pigment." The reproductions of X-rays are very good indeed, particularly one which shows a shadow of calcium deposits in a case of glioma retinae. In the treatment of this condition attention is drawn to the work of Foster Moore, Stallard and Milner in connexion with the implantation of radon seeds. The colour plates are excellent. The book has obviously found favour in the United States. We hope it will become equally well known in this country as we consider it one of the very best books of its kind on the market. Messrs. H. K. Lewis \& Co. are the English agents for supplying it.

\title{
OBITUARY
}

\section{LESLIE BUCHANAN}

THE recent death of Dr. Leslie Buchanan leaves a gap in the ranks of British ophthalmologists, and especially to his Glasgow colleagues will bring a sense of personal loss,

Born in 1868, he received his medical training in Glasgow University, where he graduated M.B., C.M., in 1898. As House Surgeon in the Glasgow Eye Infirmary, from 1891 to 1892, he decided to devote himself to ophthalmology, and having joined the visiting staff of the Infirmary, he was, in succession, Assistant Surgeon and Surgeon, retiring from the latter post soon after the Great War. For some years he held the post of pathologist to the Eye Infirmary, and in histology and photomicrography he found his chief recreation, inspired, no doubt, by the enthusiasm of his former chief, Dr. Thomas Reid.

He became a member of the Ophthalmological Society in 1901, and during the succeeding fifteen or sixteen years, made many contributions to the Transactions of the Society, mainly on pathological topics. Of outstanding interest and value were his papers on the histology of uveal disease and on birth injuries of the eye. His work on birth injury of the cornea, in conjunction with Ernest Thomson, established our knowledge of the pathology of this condition. 
For many years Leslie Buchanan played an important part in the teaching of ophthalmology, and many oculists practising in Glasgow and elsewhere, owe their early training, both pathological and clinical, to his encouragement and example. His assistants found in him an ideal chief-kindly and considerate, with a fine natural dignity and courtesy. He was modest and without affectation, and utter sincerity was the keynote of his character. To his colleagues and to his many friends, his name will be a fragrant memory.

\section{NOTES}

University of Glasgow Department of Ophthalmology Autumn Term 1943
IN September a series of meetings will be held in the Eye Department, Western Infirmary, on Wednesdays at 8 p.m. The general arrangements will be similar to the series held last year. Tea will be served after the paper and a discussion will follow. The meetings will be open to all medical practitioners and senior students interested in Ophthalmology.

September 8, Dr. J. B. Gaylor-"The fifth nerve and the cornea" ; September 15, Professor Loewenstein- "Herpes of the cornea "; September 22, Dr. J. M. Robson- "Experimental corneal ulcers "; September 29, Professor W. J. B. Riddell-" Chemical injuries of the cornea.".

The Royal Eye Hospital: Clinical Society

A meeting of the Royal Eye Hospital Clinical Society will be held at the Hospital on Friday, September 24 , at 5.30 p.m. when a talk will be given by Mr. V. E. Negus, M.S., F.R.C.S., on the following subject :- "The Relationships of Ophthalmology and Rhinology."

Special Notice

WE are asked by the Ministry of Information to state that the fact that goods made of raw materials in short supply owing to war conditions are advertised in this journal should not be taken as an indication that they are necessarily available for export. 